\title{
Modeling Bioavailable Concentrations in Zebrafish Cell Lines and Embryos Increases the Correlation of Toxicity Potencies across Test Systems
}

\author{
Sebastian Lungu-Mitea,* Carolina Vogs, Gunnar Carlsson, Maximiliane Montag, Kim Frieberg, \\ Agneta Oskarsson, and Johan Lundqvist
}

Cite This: Environ. Sci. Technol. 2021, 55, 447-457

Read Online

ACCESS | Lلll Metrics \& More | 回 Article Recommendations | st Supporting Information

ABSTRACT: Linking cellular toxicity to low-tier animal toxicity and beyond is crucial within the adverse outcome pathway concept and the 3R framework. This study aimed to determine and compare the bioavailable effect concentrations in zebrafish cell lines and embryos. Acute, short-term toxicity $(48 \mathrm{~h})$ of eight veterinary pharmaceuticals was measured in two zebrafish cell lines (hepatocytes, fibroblasts) and zebrafish embryos. Seven endpoints of cytotoxicity were recorded. The fish embryo acute toxicity test was modified by adding sublethal endpoints. Chemical distribution modeling (mass balance) was applied to compute the bioavailable compound concentrations in cells $\left(C_{\text {free }}\right)$ and embryos $\left(C_{\text {int;aq }}\right)$ based on nominal effect concentrations $\left(C_{\text {nom }}\right)$. Effect concentration ratios were calculated (cell effects/embryo effects). A low correlation was observed between cytotoxicity and

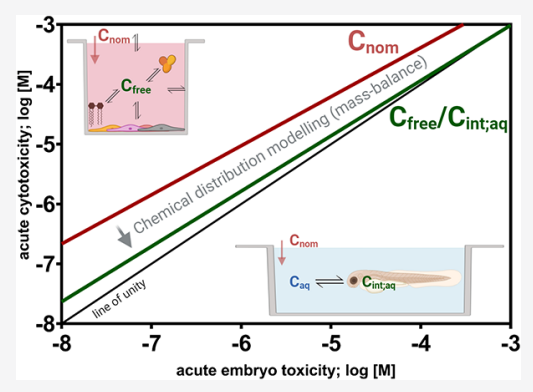
embryo toxicity when nominal concentrations were used. Modeled bioavailable effect concentrations strongly increased correlations and placed regression lines close to the line of unity and axis origin. Cytotoxicity endpoints showed differences in sensitivity and predictability. The hepatocyte cell line depicted closer proximity to the embryo data. Conclusively, the high positive correlation between the cell- and embryo-based test systems emphasizes the appropriate modulation of toxicity when linked to bioavailable concentrations. Furthermore, it highlights the potential of fish cell lines to be utilized in integrated testing strategies.

\section{INTRODUCTION}

Toxicological risk assessment and regulatory decision making, such as the REACH directive, ${ }^{1}$ TSCA reauthorization, ${ }^{2}$ and others, $^{3-6}$ have collaterally increased animal testing, ${ }^{7,8}$ a development contradictory to efforts made to reduce, replace, and refine (" $3 R s$ ") $)^{9}$ the usage of animals for both human toxicology ${ }^{10-12}$ and ecotoxicology. ${ }^{13,14}$ Given that we live in an ever-growing chemical environment, the plethora of xenobiotic compounds surrounding us needs to be assessed in ethically and economically feasible ways. ${ }^{15}$ New approach methods (NAMs) consisting of in vitro (i.e., cell-based test systems) and in silico (computer models) techniques have the potential to assess a large number of compounds ${ }^{10}$ given their compatibility with omics technologies, high-throughput screenings (HTS), and the adverse outcome pathway (AOP) concept. ${ }^{16}$ Cellular in vitro techniques are optimal sentinels for recording molecular initiating events (MIEs) and lower-tier key events (KEs) within the AOP concept but are lacking regulationrelevant apical endpoints.

Within ecotoxicology, the fish embryo acute toxicity test ("FET", OECD 236) ${ }^{1 /}$ highlighted a significant turning point in the implementation of alternative methods. In the European Union, zebrafish embryos demand no ethical permission until $120 \mathrm{~h}$ postfertilization (hpf) ${ }^{18}$ (onset of independent feeding), meaning that the FET assay is legislatively defined as an in vitro assay; biologically, it can be regarded as in vivo, especially at 120 hpf. Zebrafish embryos can be used in an HTS manner, as phenotypical changes are easily observed due to their transparency. Within the AOP concept, the FET can be utilized for the characterization of higher-tier KEs and adverse outcomes (AOs). Noteworthily, the nominal effect concentrations between the FET and the acute fish toxicity test ("AFT", OECD 203) ${ }^{19}$ are highly correlative ${ }^{20-22}$ and measurements of lethal apical endpoints at $96 \mathrm{hpf}$ are proposed to be an accurate surrogate to the AFT data. However, how well effect measurements from the FET correlate to those from cell-based assays is less studied, which is essential for bridging the in vitro to in vivo gap within the AOP concept. Therefore, the FET can be employed as a connecting platform (Figure 4).

Fish cell lines are genuine non-animal alternatives in ecotoxicology. ${ }^{13}$ Several authors considered the use of fishderived cytotoxicity assays as alternatives to in vivo assays

Received: July 21, 2020

Revised: October 28, 2020

Accepted: December 2, 2020

Published: December 15, 2020

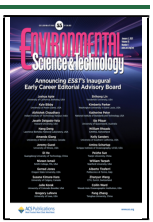


(reviewed in Castaño et al. ${ }^{23}$ ). Schirmer et al. proposed the use of fish cell lines in regulatory testing of chemicals and effluents. ${ }^{24}$ The latest efforts in this regard culminated in the publication of the rainbow trout (Oncorhynchus mykiss) cell line assay (RTgill-W1 cells) for predicting acute fish toxicity as an ISO guideline. ${ }^{25,26}$ In general, cell-based assays display lower sensitivity than in vivo techniques when comparing nominal effect concentrations $\left(C_{\text {nom }}\right)^{27-30}$ (see Table S1 for concentration nomenclature). The difference in sensitivity might be explained by the reduced or nonexisting xenobiotic metabolism, lower level of biological complexity, and reduced bioavailability of exposure compounds. ${ }^{31}$ Especially the latter is predominantly due to differences in experimental conditions ${ }^{32}$ given that fish and fish embryos are exposed in water, whereas cells are grown in complex cell culture media. The latter contain serum, protein, and lipids that act as sinks for hydrophobic compounds ${ }^{33-36}$ (especially at $\log K_{\text {ow }}>3$ ). ${ }^{32}$ Thus, the actual bioavailable concentration to the cells, the free concentration $\left(C_{\text {free }}\right)$, is only a fraction of $C_{\text {nom }}$. Contextually, antecedent attempts at comparing toxic potencies between fish cells and whole fish test systems resulted in weak correlations. $^{37}$

Two principal strategies emerged to address a weak correlation due to bioavailability differences between test systems. The first is by measuring the real exposure concentrations via chemical analysis. Tanneberger et al. and Natsch et al. successfully conducted such an approach in the RTgill-W1 cell line, ${ }^{38,39}$ indeed showing an improved correlation. However, extraction and chemical analysis are time-consuming, are costly, and hamper high-throughput testing of chemicals. The second strategy relates to modeling bioavailable concentrations as a better dose metric for biologically effective concentrations. By using chemical distribution models (mass-balance model, "MBM"), differences in chemical partitioning between lipids and proteins are accounted for, increasing the comparability of biologically effective concentrations between test systems. Recently, appropriate MBMs were developed for cell-based assays ${ }^{40}$ and the FET. ${ }^{41}$ Generally, modeling has the advantage of omitting extraction and chemical analysis, making it a considerably more straightforward approach. ${ }^{31}$

Recently, Rodrigues et al. claimed high correlations in nominal effect concentrations for pharmaceuticals ${ }^{42}$ but not for pesticides ${ }^{43}$ when comparing cytotoxicity data derived from rat cardiomyoblasts and the literature with AFT data. The pesticide study caused subsequent controversies, ${ }^{44,45}$ thus highlighting the topicality and importance of the issue. Additionally, Villeneuve et al. recently reviewed the state of the science in environmental high-throughput screening, ${ }^{46}$ and they proposed the assessment of bioavailable concentrations in cells $\left(C_{\text {free }}\right)$ and fish $\left(C_{\text {int }}\right)$ for a proper comparison and correlation.

This study aimed to compare the acute, short-term toxicity between two permanent zebrafish (Danio rerio) cell lines (hepatocytes, fibroblasts) and the zebrafish embryo. We hypothesized that the cell-derived cytotoxicity data correlate appropriately with the modified-FET (mFET) data when modeled bioavailable effect concentrations are considered instead of nominal effect concentrations. To this end, we generated acute toxicity data for eight veterinary pharmaceuticals, covering different compound classes. We employed the MBMs developed by Fischer et $a .^{40}$ for the cell lines and by
Bittner et al. ${ }^{41}$ for the mFET assay and evaluated the nominal and modeled bioavailable effect concentrations.

\section{MATERIALS AND METHODS}

A detailed description of all relevant materials and methods is given in the Supporting Information 1, Section 1.1. The important aspects are condensed in the following:

Eight veterinary pharmaceuticals were purchased from Sigma-Aldrich, Steinheim, Germany (albendazole (Abz), doramectin (Dor), febantel (Feb), fenbendazole (Fen), flumethrin (Flu), ivermectin (Ive), oxfendazole (Ox), and toltrazuril (Tol); all >95\% purity, Supelco or VETRANAL analytical standards).

ZF4 (fibroblasts) and ZFL (hepatocytes) cell lines were purchased from ATCC (Manassas, VA, USA). The culturing procedures are described in the Supporting Information 1, Section 1.1.2 and prior publications. ${ }^{47,48}$ The cells were exposed to eight increasing concentrations of the veterinary pharmaceuticals. Exposure ranges were defined in pilot experiments. After $48 \mathrm{~h}$ of exposure, seven different endpoints of cytotoxicity (in vitro biomarker of toxicity) were recorded via three different multiplex assays. $\mathrm{NAD}(\mathrm{P}) \mathrm{H}$ metabolism and protein amount were recorded using the dimethylthiazoltetrazolium salt (MTS) and bicinchoninic acid (BCA) multiplex assay. ATP metabolism and membrane stability were recorded using the adenosine triphosphate (ATP) and lactate dehydrogenase (LDH) multiplex assay. ${ }^{48,49}$ Aerobic cellular respiration and membrane and lysosome stability were recorded using the alamarBlue $(\mathrm{AB})$, carboxyfluorescein diacetate acetoxymethyl ester (CFDA), and neutral red (NR) multiplex assay. The $\mathrm{AB} / \mathrm{CFDA} / \mathrm{NR}$ multiplex assay was conducted according to the Schirmer group ${ }^{26,50-53}$ with alterations made by Bopp and Lettieri ${ }^{54}$ and ourselves to employ serum-mediated passive dosing. ${ }^{55,56}$ Both absorbance (NRa) and fluorescence (NRf) were recorded for the NR endpoint. Nominal median inhibitory concentrations $\left(\mathrm{IC}_{50 \text {;nom }}\right)$ (Table S1) of the cytotoxicity endpoints were computed by a four-parameter log-logistic regression, with alternations described by Weimer et al. ${ }^{57}$ and plotted in GraphPad Prism 8 (GraphPad Software, La Jolla, CA, USA).

For the zebrafish embryo data, methodologies and results of the modified fish embryo test (mFET; addition of sublethal endpoints to standard FET apical endpoints) after $144 \mathrm{~h}$ of exposure are described in detail in Carlsson et al. ${ }^{58}$ and the Supporting Information, Sections 1.1.5-6. For this study, the raw data at $48 \mathrm{hpf}$ were retrieved and analyzed. Nominal median effect concentrations $\left(\mathrm{EC}_{50 \text {;nom }}\right)$ of the embryo toxicity were computed by probit regression and plotted using Minitab 18.1 (Minitab Inc., State College, PA, USA).

Chemical distribution models (mass-balance model, "MBM") were applied to derive the bioavailable concentrations and protein/lipid-bound fractions. The Fischer et al. ${ }^{40}$ MBM was used to compute the respective bioavailable median concentrations in the cell lines $\left(\mathrm{IC}_{50 \text {;ree }}\right)$, whereas the Bittner et al. ${ }^{41}$ MBM was used for the embryo $\left(\right.$ IAEC $_{50}$ ). Distribution coefficients of all veterinary pharmaceuticals between relevant phases, as they are mandatory for the MBM input, were obtained via the UFZ-LSER tool ${ }^{59}$ (Supporting Information 2, sheet "LSER").

$\mathrm{IC}_{50 \text {;nom }}$ and $\mathrm{IC}_{50 \text {;ree }}$ were divided by $\mathrm{EC}_{50 \text {;nom }}$ and $\mathrm{IAEC}_{50}$, respectively, to display the potency ratios. Nominal and bioavailable median effect/inhibitory concentrations were logtransformed, tested for normality by Shapiro-Wilk and 
Kolmogorov-Smirnov tests $(P=0.05)$, and analyzed graphically by a normal $q-q$ plot. Pearson correlation coefficients between all cell- and embryo-derived data were computed (Supporting Information 2, sheet "correlation"), and adjusted $R^{2}$ values were illustrated in heatmaps. Deming (Model II) linear regression was performed to obtain regression equations (Supporting Information 2, sheet "regression"). Statistical testing and plotting were conducted with GraphPad Prism 8.

\section{RESULTS AND DISCUSSION}

Within ecotoxicology, there is an ongoing debate as to what extent are cellular in vitro systems a feasible approach in toxicity testing and risk assessment. There still seems to be uncertainty in using nominal concentrations rather than bioavailable concentrations, as demonstrated in the Rodrigues et al. controversies. ${ }^{44,45}$ In this study, we first demonstrated how modeling bioavailable effect concentrations strongly increased the correlation between zebrafish cell lines and embryo-derived data for the eight tested veterinary pharmaceuticals. We then tested if the approach improved the correlation for pesticides, as utilized by Rodrigues et al.

Acute Toxicity in Zebrafish Cells. Seven different endpoints of cytotoxicity were recorded after exposure to eight veterinary pharmaceuticals comprising different classes of organic compounds (Table S2; Supporting Information 2, sheet "properties"). A four-parameter log-logistic regression with additions, according to Weimer et al., ${ }^{57}$ was performed to compute respective $\mathrm{IC}_{50 \text {;nom }}$ (Figures S4-S19; Table S3; Supporting Information 2, sheet "cell data"). Note that the lactate dehydrogenase ( $\mathrm{LDH}$ ) endpoint was excluded from further analyses given that the response data were poorly described by the log-logistic regression model, as indicated by the low adjusted $R^{2}$ and high normalized RSME values, most likely due to the nonmonotonous concentration-response characteristics (Table S3; Figures S4-S19, panel D). A more detailed discussion of the latter is given in Supporting Information 1, Section 2.2. The tested compounds depicted a range of potencies with the mean $\log \mathrm{IC}_{50 \text {;nom }}$ spanning from -3.64 (Flu) to -5.62 (Fen) $\log [\mathrm{M}]$ (Figure S21). Some compounds (Dor, Feb, Flu, Ive, Tol) showed less, whereas others $\left(\mathrm{Abz}\right.$, Fen, Ox) showed more scattered $(\log ) \mathrm{IC}_{50 \text {;nom }}$ values (Figure S21; Supporting Information 2, sheet "cell data"). The pattern is also represented in the potency ratios of the nominal median concentration $\left(\mathrm{IC}_{50 \text {;nom }} / \mathrm{EC}_{50 \text {;nom }}\right)$, which are discussed further below (Figure 1A).

When comparing $\mathrm{IC}_{50 \text {;nom }}$ values between different cytotoxic endpoints, the BCA endpoint seemed to be the most sensitive, whereas the CFDA endpoint was the least sensitive (Figure S21). However, the pattern is not consistent with BCA-ZFL, being the least sensitive endpoint after flumethrin exposure, and might thus derive from technical abnormalities. On the contrary, Natsch et al. found the CFDA endpoint to be the most sensitive out of the $\mathrm{AB} / \mathrm{CFDA} / \mathrm{NR}$-triplex assay ${ }^{39}$ when testing the acute toxicity of fragrance chemicals. However, the authors regarded the differences in sensibility as negligible given that all three endpoints were highly intercorrelated. The endpoints of energy metabolism (MTS-ZFL, MTS-ATP) are more sensitive in the ZFL cell line exposed to albendazole (Figure S21A) and fenbendazole (Figure S21D). However, this was not confirmed for the ZF4 cell line. The other cytotoxicity endpoints are located close to their respective log $\mathrm{IC}_{50 \text {;nom }}$ means. Conclusively, we would mostly recommend the $\mathrm{AB}$ / CFDA/NR-triplex assay ${ }^{26}$ given its applicability, the total
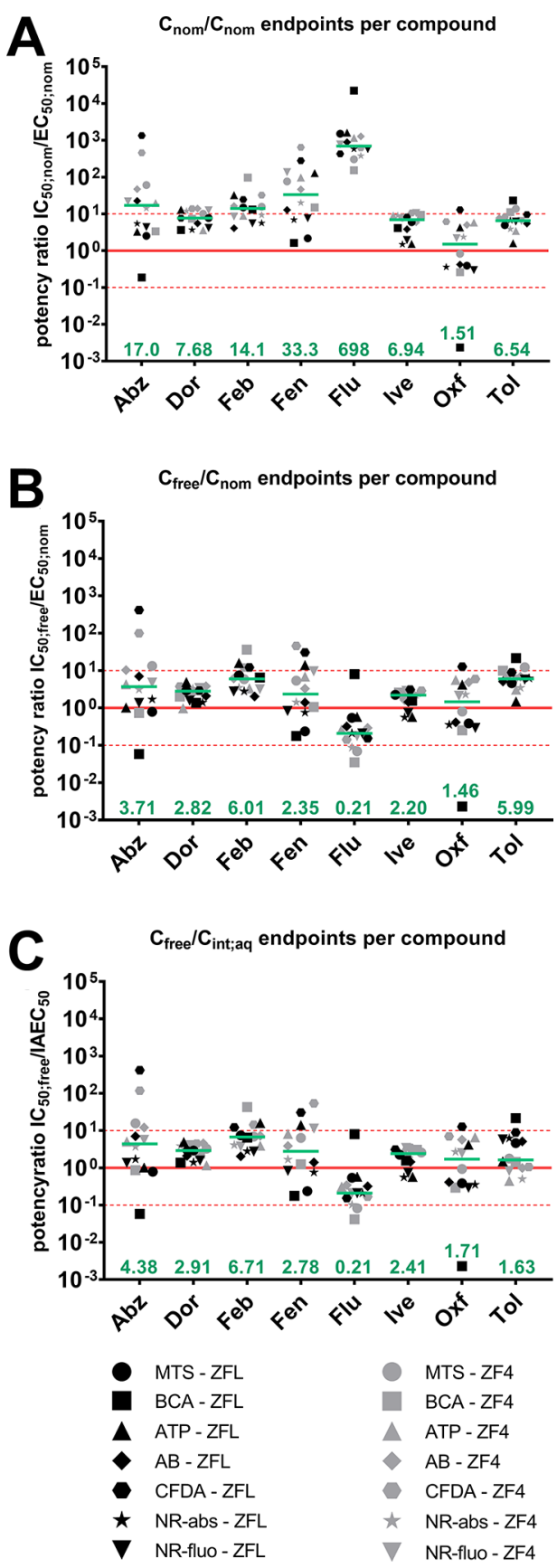

Figure 1. Potency ratios of median inhibitory concentrations of the cellular cytotoxicity assays vs median effect concentrations of the mFET assays $\left(\mathrm{IC}_{50 ; x} / \mathrm{EC}_{50 ; x}\right)$. The ratios are plotted as an endpoint of cellular toxicity per tested compound. Potency ratios are based on nominal concentrations $\left(\mathrm{A} ; \mathrm{IC}_{50 ; \text { nom }} / \mathrm{EC}_{50 ; \text { nom }}\right)$, modeled free concentrations $\left(\mathrm{B} ; \mathrm{IC}_{50 \text {;ree }} / \mathrm{EC}_{50 \text {;nom }}\right)$, or modeled internal concentrations $\left(\mathrm{C} ; \mathrm{IC}_{50 \text {;ree }} / \mathrm{IAEC}_{50}\right)$. The median value of all compounds per endpoint is marked with a green line and depicted above the $x$ axis. The line of unity at $10^{\circ}=1$ is marked with a red line; \pm 1 order of magnitude deviations are marked with dotted red lines.

number of scored endpoints, and its overall sensitivity and correlation. The relationship of cellular cytotoxicity endpoints to apical endpoints of the mFET is discussed further below in more detail.

Supposedly, compounds might operate via different modes (MoAs) and mechanisms of action (MOAs) and are therefore impacting endpoints differently, leading to diverse patterns of 
sensitivity. Compounds with narrow endpoint distributions and similar $\mathrm{IC}_{50 \text {;nom }}$ values (Table S3; Figure S21; Supporting Information 2, sheet "cell data") may display the same MOA, most likely baseline toxicity (narcosis), whereas compounds with broad endpoint distributions may display a range of distinct MOAs that are differentially reflected in the tested endpoints. Neurotoxins were reported to induce baseline toxicity in RTgill-W1 cell lines. ${ }^{38}$ The neurotoxin flumethrin had the lowest overall toxic potency in the cell lines. Contrarily, the other neurotoxins (Dor, Iver) displayed stronger toxic potencies than some of the tested benzimidazoles (Feb, Ox), which have a specific MOA in target organisms (Table S2). Thus, neither MOAs nor MoAs are conserved in nontarget organisms, especially not in the cell lines. Some of the compounds (Feb, Flu, Tol) might be considered to be acting via a baseline toxicity MOA, whereas the others (Abz, Dor, Fen, Iver, Ox) have different MOAs in the cell lines. However, no realistic interference can be made by the generated patterns or used compound classes, especially not in an MoA manner, which was also not the intention of the conducted study.

The $\mathrm{IC}_{50 \text {;nom }}$ values for five out of the eight tested compounds (Abz, Dor, Feb, Fen, Ox) were compared to available CompTox bioactivity data (https://comptox.epa. gov/dashboard/) to check for data integrity. Mammalian data validated the zebrafish cell line results (Supporting Information 2, sheet "cell data") and correlated well in qualitative terms. More detailed information is given in Supporting Information 1, Section 2.4.1.

Acute Toxicity in Zebrafish Embryos. The effects of the eight veterinary pharmaceuticals on the zebrafish embryo have been discussed in detail in Carlsson et al. ${ }^{58}$ for the $144 \mathrm{hpf}$ time point. The median effect concentrations $\left(\mathrm{EC}_{50 \text {;nom }}\right)$ at $48 \mathrm{hpf}$ that were extracted from the original data and computed for this study (Figure S20; Supporting Information 2, sheet "mFET data") differed in comparison to those at 144 hpf. For some compounds, $\mathrm{EC}_{50 \text {;nom }}$ is approximately the same between time points (Abz, Fen, Flu, Ox), whereas for the others, the difference in toxicity is approximately 10-fold (Dor, Feb, Ive, Tol), with the $48 \mathrm{hpf}$ time point being one log-scale less sensitive. The toxicity differences between time points might be due to bioaccumulation (enhanced uptake due to chorion detachment), bioactivation, or different susceptible developmental windows. ${ }^{60,61}$ In terms of potency, the $\mathrm{EC}_{50 \text {;nom }}$ values, derived from the apical and sublethal endpoints in the mFET, depict a wide range from $-7.11 \log [\mathrm{M}]$ (Fen) to $-4.61 \log [\mathrm{M}](\mathrm{Ox})$ (Table S4; Figure S22).

A survey was conducted in the Ecotox database (https:// cfpub.epa.gov/ecotox/search.cfm) to check the integrity of the fish embryo data. Unfortunately, comparable data were only retrieved for ivermectin. Two other studies showed proportionate $\mathrm{EC}_{50 \text {;nom }}$ values at 48 and $144 \mathrm{hpf}$ in zebrafish embryos and larvae. ${ }^{62,63}$ For all other compounds, no fish-related data were found; only studies in plants or invertebrates are available.

Nominal Median Effect/Inhibitory Concentrations: Cell Lines vs Embryo. When comparing $\mathrm{EC}_{50 \text {;nom }}$ values (embryo) to $\mathrm{IC}_{50 \text {;nom }}$ values (cells), there is a general 10-fold (one log-scale) difference in sensitivity between the embryo and cell test systems, with the compounds showing higher potency in the mFET (Table S5; Figure S23). Three compounds differ from the general pattern. Flumethrin and fenbendazole are two to three log-scales more sensitive in the
mFET, whereas oxfendazole shows equal nominal median concentrations between test systems. Flumethrin took on a particular position. For flumethrin, only the sublethal endpoints were recorded in the mFET assay (Figure S20E), and the probit regression model fit was suboptimal (Table S4). Additionally, flumethrin displays the highest $\log K_{\mathrm{ow}}$ (6.97, see Table S2) of all tested compounds. In terms of nominal concentrations, flumethrin shows the lowest toxicity in the cytotoxicity assays (Figure 1A; Figure S21E) and deviates the strongest from the calculated regression lines (Figure 3A). Hence, we decided to also display the data without flumethrin (respective graphs in Supporting Information 1), considering that it might be due to technical incompatibilities.

We calculated the potency ratios $\left(\mathrm{IC}_{50 ; x} / \mathrm{EC}_{50 ; x}\right)$ for nominal effect/inhibitory concentrations (Figure 1 ). The potency ratios are a measure of the test system's sensitivity: ratios of compounds depicting a higher potency in the mFET assay are located above the line of unity, and ratios depicting a higher potency in the cytotoxicity assays are located below the line of unity. As for the numeric median concentrations, we see an approximately 10-fold difference in potency (Figure 1A; Figure S22A) with similar outliers ( $\mathrm{Ox}$, Flu), thus indicating major differences to the other compounds in toxicokinetic and toxicodynamic perspectives.

The median potency ratio value of oxfendazole (1.51; Figure 1 , green line) is almost on the line of unity, with more than half of the endpoints' potency ratios being more sensitive in the cell-based assays. Besides that, only the BCA endpoint measured for cells exposed to albendazole is more sensitive. Correspondingly, Gülden and Seibert ${ }^{29}$ reported minor differences in nominal effect concentrations between in vitroand in vivo-derived effect concentrations for less cytotoxic compounds. For compounds with a low cytotoxic potency, the reduction in bioavailability due to binding to medium ingredients was less significant because binding might be saturated at the chemical concentration needed to elicit toxicity. Accordingly, oxfendazole caused the lowest toxicity in the mFET assay (Table S5; Supporting Information 2, sheet "mFET data"), explaining the good correlation already for $C_{\text {nom }}$.

Flumethrin deviates largely in nominal median inhibitory/ effect concentrations between cells and embryos (Table S5; Figure S23A). The potency ratio median (Figure 1A) is 698fold less sensitive in the cell-based assays and for one endpoint (BCA-ZFL) even 10,000-fold. The presence of tremors in the embryos (sublethal endpoint) accounted for most of the recorded effects. The latter reflects flumethrin's potential neurotoxic mode of action (MoA) in the mFET. Arguably, flumethrin might act as a neurotoxin in the fish embryo already at $48 \mathrm{hpf}$ as this observation is similar to the $144 \mathrm{hpf}$ time point $^{58}$ (Figure S25A). The FET has been reported to be less sensitive to neurotoxins in comparison to the AFT. ${ }^{21}$ RTgillW1 cells showed reduced sensitivity to neurotoxins in comparison to in vivo data. ${ }^{38,64}$ The detection of neurotoxicity in the embryo test is, however, due to the inclusion of sublethal endpoints (mFET). This effect would not have been recorded if only the standard lethal endpoints described for the FET test ${ }^{17}$ were used. Since an adequate in vitro assessment of neurotoxins requires neural cells expressing particular intrinsic transporter and membrane receptor proteins (e.g., dopaminergic and glutamatergic), ${ }^{65}$ permanent fish fibroblasts (ZF4) and hepatocytes (ZFL) are not appropriate. Beyond that, flumethrin has the lowest water solubility of all tested 


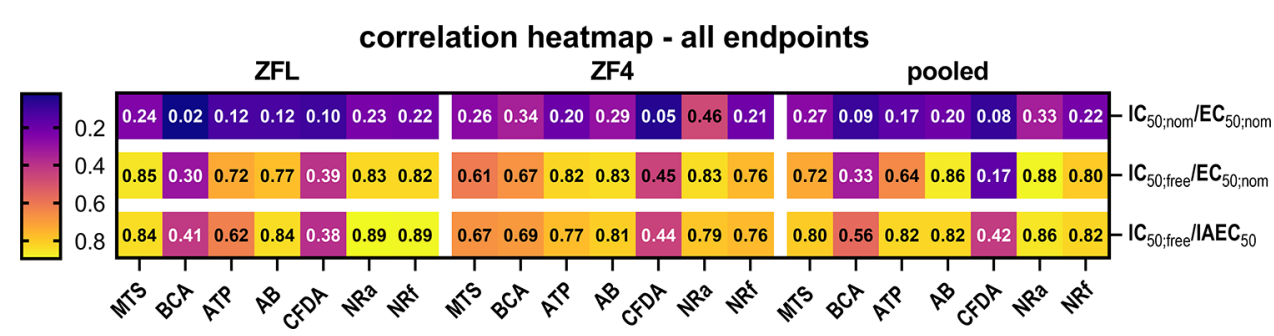

Figure 2. A heatmap of adjusted $R^{2}$ values derived from Pearson correlation of the various $\mathrm{IC}_{x}$ (cells) vs $\mathrm{EC}_{x}$ (fish embryos) comparisons per endpoint of cellular toxicity. Correlations of nominal and bioavailable median concentrations are depicted for ZFL, ZF4, and pooled cell lines (column stacks). For significance levels and $P$ values of Pearson correlations, see also Supporting Information 2, sheet "correlations". Additionally, a correlation heatmap without flumethrin and without neurotoxins is available in Supporting Information 1 (Figure S26).

compounds $\left(5.95 \times 10^{-07} \mathrm{M}\right.$; Table S2). Potentially, in an aqueous environment, maximally solved concentrations before precipitation are not high enough to cause a baseline toxicity effect, which is most likely recorded here with the cellular assays (range from $2.41 \times 10^{-07}$ to $6.13 \times 10^{-03} \mathrm{M}$ ). However, as mentioned previously, apical endpoints within the mFET and nonspecific cytotoxicity endpoints, as recorded in the cell lines, do not bare sufficient mechanistic information to draw potential conclusions on specific MOA and MoA.

Pearson-derived correlations between $\mathrm{IC}_{50 \text {;nom }}$ and $\mathrm{EC}_{50 \text {;nom }}$ values (Figure 2) were weak and statistically nonsignificant for both cell lines as well as the pooled cytotoxicity data (adj. $R^{2}$ range from 0.02 (BCA-ZFL) to 0.46 (NRa-ZF4); see also Supporting Information 2, sheet "correlation"). If flumethrin was excluded, overall correlations were increasingly compelling $\left(R^{2}=0.96\right.$ (NRa-ZF4), Figure S26). However, since the dataset gives no insights into the mechanisms of toxicity, such an exclusion remains tentative. Nevertheless, the potential exclusion of flumethrin indicates how bioavailability potentially modulates toxicity given that flumethrin depicts the most substantial discrepancy in terms of nominal concentrations (Figure S23A). Generally, the correlation coefficients are higher for ZF4 than for ZFL. Notably, the ZF4 nutrition medium contains double the amount (10\%) of FBS than ZFL (5\%). A higher amount of FBS in the nutrition and exposure medium has been reported to be associated with enhanced uptake kinetics in cells. ${ }^{55}$ Thus, the equilibrium at the target site might be reached earlier in a high-FBS scenario, leading to a more sensitive measure of the nominal median concentration. Nevertheless, since both FBS concentrations used are relatively high, uptake kinetics-mediated effects might be marginal within a $48 \mathrm{~h}$ exposure regime. Hence, other factors such as cell line origin, overall density, and mass or general biological sensitivity might be crucial.

Bioavailable Median Effect/Inhibitory Concentrations Increased Goodness-of-Fit: Cell Lines vs Embryo. We hypothesized that modeling bioavailable median effect/ inhibitory concentrations ( $\mathrm{IC}_{50 \text {;free; }} \mathrm{IAEC}_{50}$ ) would significantly increase the correlation between the cell- and embryoderived data. To test our hypothesis, we applied two state-ofthe-science MBMs to estimate the bioavailable concentrations for the cells ${ }^{40}$ and the embryo. ${ }^{41}$ Noteworthily, these chemical distribution models are based on empirical protein and lipid content data derived from the fish embryos and cell culture media.

Modeling the bioavailable concentration in the medium $\left(C_{\text {free }}\right)$ according to Fischer et al. ${ }^{40}$ (Supporting Information 2, sheet "Model Fischer2017") disclosed an increased potency of the cell-derived measures (Figure 1B; Figures S21 and S23).
Accordingly, Kramer et al. ${ }^{30}$ observed the nominal effect concentrations being approximately 10 -fold higher than the bioavailable effect concentration for phenanthrene in Balb/c 3T3 and RTgill-W1 cells. For six out of the eight tested compounds (Abz, Dor, Feb, Fen, Flu, Iver), the modeled bioavailable concentrations differed statistically from the nominal concentrations (Figure S21). The bioavailable concentrations for fenbendazole and flumethrin differed by more than one log-scale. Oxfendazole and toltrazuril barely showed any differences between the nominal and bioavailable inhibitory concentrations. Modeling the bioavailable aqueous internal effect concentration $\left(C_{\text {int;aq }}\right)$ according to Bittner et al. ${ }^{41}$ did not indicate significant alternations in compound potencies, except for toltrazuril (Figure S22).

$C_{\text {free }}$ of fenbendazole and flumethrin showed the highest discrepancies to $C_{\text {nom }}$. It is evident how binding to medium components drastically reduces their bioavailability within the in vitro systems. Once the actual bioavailable concentrations are computed and related to the bioavailable concentrations in the mFET system, the differences in sensitivity and potency are relatively small. We discussed that $\mathrm{IC}_{50 \text {;nom }}$ and $\mathrm{EC}_{50 \text {;nom }}$ of oxfendazole were already showing a high similarity, most likely due to hydrophilicity. Thus, $C_{\text {nom }}$ and $C_{\text {free }}$ are practically equal, and the culture medium ingredients are only marginally affecting the bioavailability. Toltrazuril was the only tested zwitterionic compound that is not $>99 \%$ encountered in its neutral form at physiological $\mathrm{pH}$ (Supporting Information 2, sheet "Model Bittner2019"). Given that toltrazuril has the lowest $\mathrm{p} K_{\mathrm{a}}$ value (6.47) of all tested compounds, it will likely have a representative amount of ionized species at physiological $\mathrm{pH}$. In an aquatic environment, toltrazuril will bioconcentrate to a lesser extent than the other compounds. ${ }^{66}$ Ionic species feature different sorption preferences than neutral organic compounds, as they increasingly partition into phospholipids and structural protein, ${ }^{67}$ and they are susceptible to an ion-trapping effect if the $\mathrm{pH}$ of the exposure medium is lower than the internal $\mathrm{pH}$ of the organism. ${ }^{66}$

Regarding the $\mathrm{IC}_{50 \text {; free }} / \mathrm{EC}_{50 \text {; nom }}$ comparison, median potency ratios are located underneath the upper 10-fold borderline and close to the line of unity for all compounds and endpoints (0.21-6.01; Figure 1B; Figure S24B). As above, the median potency ratios remained almost equal for the $\mathrm{IC}_{50 \text {;ree }} / \mathrm{IAEC}_{50}$ comparison but also with toltrazuril almost located on the line of unity (1.63; Figure 1C). The differences in sensitivity between test systems and potencies of compounds are rather negligible once the actual bioavailable effect/inhibitory concentrations are considered. Interestingly, the differences between $C_{\text {nom }}$ and $C_{\text {int;aq }}$ were more pronounced in the ZF4 cell line. As stated above, ZF4 uses 
twice the amount of FBS as ZFL; sorption to structural protein, mostly within the serum, is expected for ionic chemicals. Accordingly, the bioavailable effect/inhibitory concentrations are appropriately represented after the modeling procedures.

The similarity in bioavailable effect/inhibitory concentrations between the two test systems is further reflected in the computed Pearson correlations (Figure 2) when comparing the nominal concentration arrangement $\left(\mathrm{IC}_{50 \text {;nom }}\right.$ vs $\mathrm{EC}_{50 \text {;nom }}$ ) against the bioavailable concentration arrangements $\left(\mathrm{IC}_{50 \text {;ree }}\right.$ vs $\mathrm{EC}_{50 \text {;nom; }} \mathrm{IC}_{50 \text {;rree }}$ vs $\mathrm{IAEC}_{50}$ ), with adj. $R^{2}$ up to 0.89 (NR endpoints in ZF4). The Pearson correlations are even further increased when specific data are omitted, e.g., without Flu and without neurotoxins, with adj. $R^{2}$ up to 0.99 (NRa-ZF4; Figure S26). However, as already mentioned, such an exclusion remains tentative given that mechanistic exclusions cannot be made with the dataset at hand. According to the potency ratios, $C_{\text {int;aq }}$ had barely any impact on the correlations $\left(\mathrm{IC}_{50 \text {; free }}\right.$ vs IAEC $_{50}$ ), with some endpoints showing marginally higher or lower values. This reflects well how the bioavailable concentrations differ only for toltrazuril from the nominal concentrations in the mFET system. Overall, the ZFL cell line shows a better fit for the embryo-derived data, the NR endpoints correlate best, and the BCA and CFDA endpoints have the lowest correlations for all the nominal and bioavailable concentrations.

Type II linear regression (Deming) was conducted to identify goodness-of-fit between the cell- and embryo-derived concentrations. The results are shown in Table S6 for the entire dataset and illustrated in Figure 3 for the pooled NRa endpoint. The NRa endpoint for pooled cell lines depicted the overall strongest correlations (Figure 2), and its regression analyses showed statistically significant deviation from zero in all tested setups $(P<0.05$; Table S6). Therefore, the latter was plotted here in detail (Figure 3 ). $C_{\text {nom }}$ (Figure $3 \mathrm{~A}$ ) shows rather low correlations (adj. $R^{2}=0.33$ ); e.g., the flumethrin values are remotely located from the regression fit $(f(x)=$ $0.82 x-0.11)$. For $C_{\text {free, }}$ the fit for NRa-pooled increases (adj. $R^{2}=0.88$; Figure $3 \mathrm{~B}$ ) as well as for all other endpoints tested, with all setups becoming statistically significant except for CFDA-ZF4, CFDA-ZFL, and BCA-ZFL $(P<0.05$; Table S6, data not illustrated graphically). Above, we described how considering $C_{\text {int;aq }}$ only marginally altered correlations. However, Figure $3 \mathrm{C}$ illustrates how the goodness-of-fit is influenced by also regarding the bioavailable concentrations in the mFET system. Now, the regression line is almost on par with the line of unity $(f(x)=1.1 x+0.68)$. This holds true for the depicted endpoint as well as every other recorded endpoint and setup (Table S6). In parallel to the calculated Pearson correlations, when omitting certain data, correlation and fit are further enhanced (Figure S29). Conclusively, the Deming regression analysis proved how $C_{\text {free }}$ and $C_{\text {int;aq }}$ relate between both investigated test systems, nearly to the point of absolute unity.

Internal and Structural Lipid Median Effect/Inhibitory Concentrations: Cell Lines vs Embryo. We intended to investigate as to what extent the total internal concentrations $\left(C_{\text {cell }}\right.$ vs $\left.C_{\text {int }}\right)$ and internal partitioning to structural lipid $\left(C_{\text {mem }}\right.$ vs $\left.C_{\text {int;lip }}\right)$ would correlate. Consequently, we modeled the internal cellular concentration $\left(C_{\text {cell }}\right)$ and cellular membrane concentration $\left(C_{\text {mem }}\right)$ in the cytotoxicity assays by using the Fischer et al. ${ }^{40}$ model. Furthermore, we modeled the total internal concentration $\left(C_{\text {int }}\right)$, the critical membrane
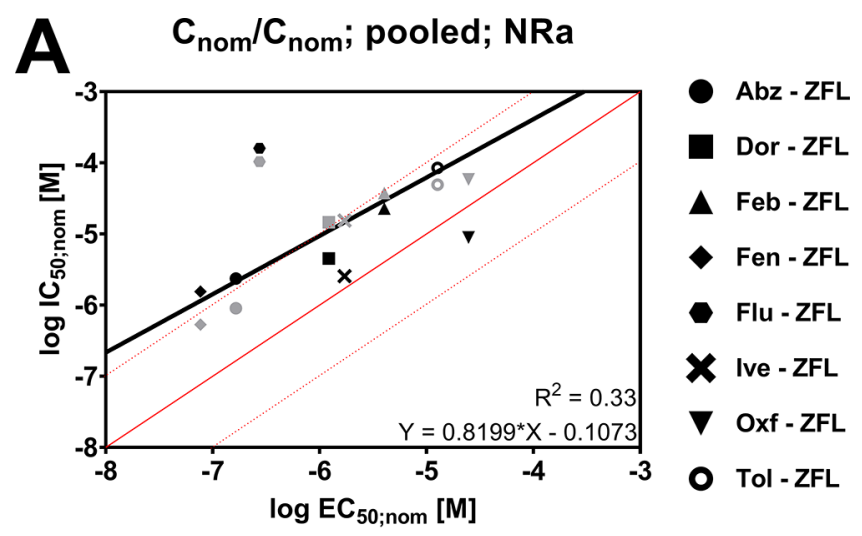

D $\mathrm{C}_{\text {free }} / \mathrm{C}_{\text {nom; }}$ pooled; NRa

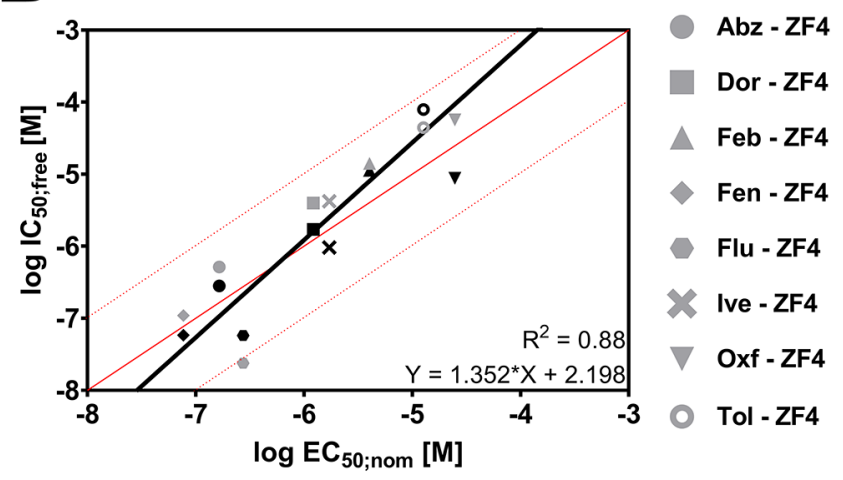

C $\quad \mathrm{C}_{\text {free }} / \mathrm{C}_{\text {int; ;q }} ;$ pooled; NRa

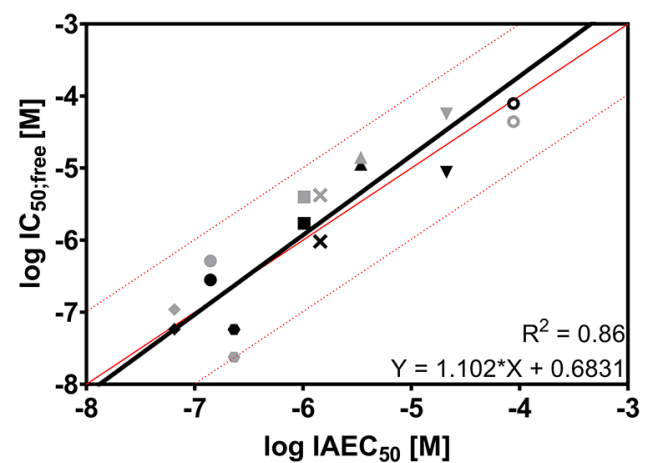

Figure 3. Deming regression of depicted $\mathrm{IC}_{x}$ (cells) and $\mathrm{EC}_{x}$ (fish embryo) values for pooled cell lines $(\mathrm{ZF} 4+\mathrm{ZFL})$ and the NRa (neutral red, absorbance) endpoint of cellular toxicity. The regression line is plotted in solid black, the line of unity is in solid red, and 1 order of magnitude deviations from the line of unity are plotted as dotted red lines. Regression equations and adjusted $R^{2}$ values of Pearson correlations are given for every setup of comparison. Significant positive linear relationships were found for all setups depicted here (for the total dataset, see also Table S6): $\log \mathrm{IC}_{50 \text {;nom }}$ vs $\log \mathrm{EC}_{50 \text {;nom }}(\mathrm{A}), \log \mathrm{IC}_{50 \text {; free }}$ vs $\log \mathrm{EC}_{50 \text {;nom }}(\mathrm{B})$, and $\log \mathrm{IC}_{50 \text {; free }}$ vs $\log \operatorname{IAEC}_{50}(\mathrm{C})$.

concentration $\left(C_{\text {int;lip }}\right)$, and the internal protein-bound concentration $\left(C_{\text {int; prot }}\right)$ in the zebrafish embryo via the Bittner et al. $^{41}$ model.

Unexpectedly, correlations and predictions are less prominent as for the bioavailable concentrations (Table S7; Figure S27; Supporting Information 2, sheets "correlation" and "regression"), with adj. $R^{2}$ values ranging from 0.27 ( $\mathrm{IC}_{50 \text { :cell }} /$ $\left.\mathrm{IEC}_{50}, \mathrm{BCA}-\mathrm{ZF} 4\right)$ to $0.86\left(\mathrm{IC}_{50 \text { :mem }} / \mathrm{IEC}_{50 ; \text { lip }}\right.$ MTS-ZF4). 


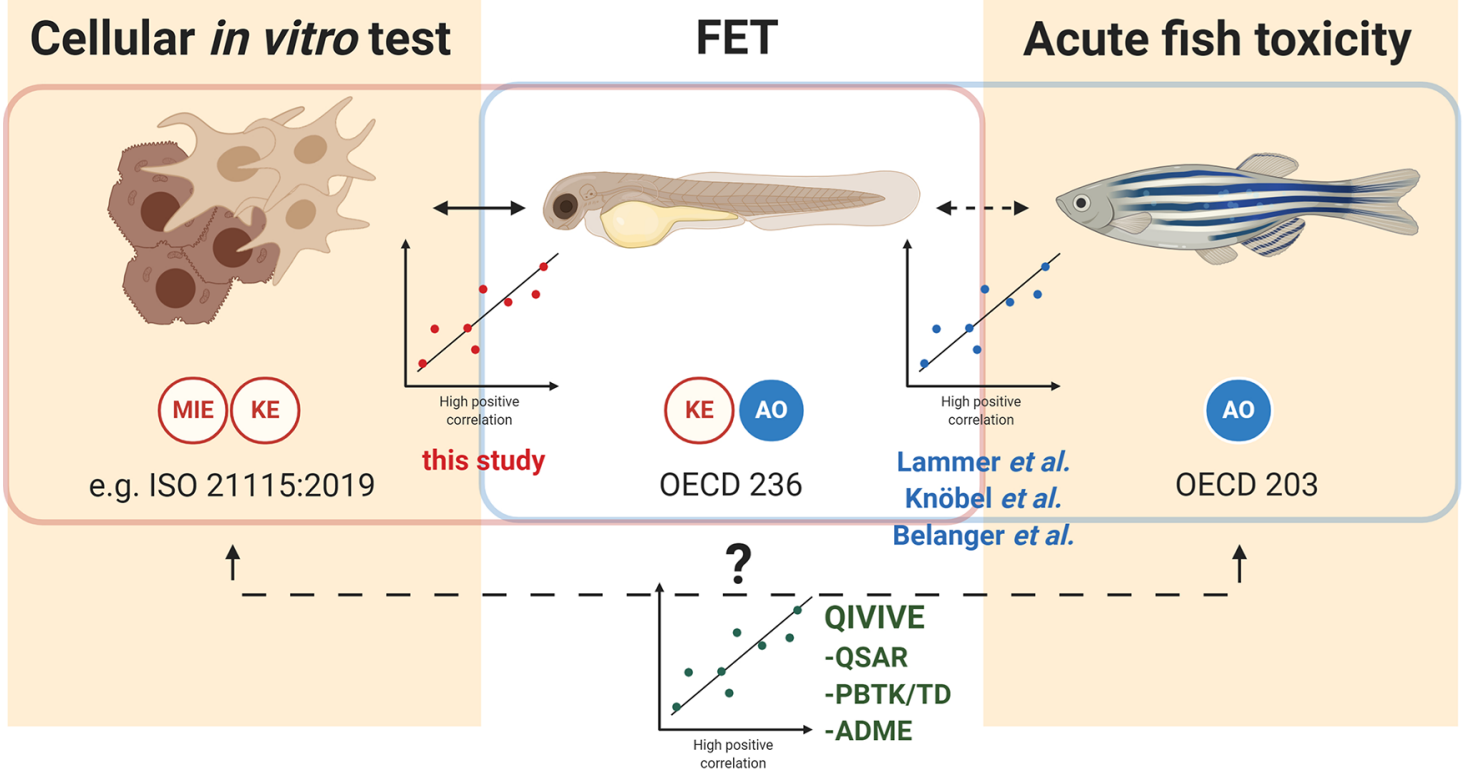

Figure 4. Fish embryo test (FET), and therefore fish cytotoxicity assays, can be used as a bridging technology in integrated test strategies (ITS) for the correlation of in vivo acute toxicity data until appropriate quantitative in vitro to in vivo extrapolation (QIVIVE) is also available in an ecotoxicological context. The illustration was generated in the licensed BioRender application.

Nevertheless, only 6 out of the 42 tested arrangements did not show statistical significance for correlations $(P<0.05)$. Previous studies also encountered varying predictions between internal fish and internal cell concentrations, which most likely occur due to differences in toxicokinetics between the investigated biological systems. ${ }^{64}$ Moreover, various studies recommended to compare modeled or measured in vitro $C_{\text {free }}$ to nominal in vivo effect concentrations $\left(\mathrm{EC}_{\text {nom }}\right.$ or $\left.\mathrm{LC}_{\text {nom }}\right)$ or, if available, unbound plasma concentrations. ${ }^{31,40,68-70}$ While applying the Bittner et al. ${ }^{41}$ model, we decided to use the $C_{\text {int;aq }}$ metric for comparison given that the internal aqueous concentration resembles the unbound and bioavailable fraction of the compounds in fish embryos best and thus mimics $C_{\text {free }}$ in the cell-based assays.

Noteworthily, none of the used biological and physicochemical parameters in the models had been measured, but all were derived from literature and average values. Still, the latter conceptually proves the robustness of the models to predict bioavailable effect concentrations even without precise parameter detections. Theoretically, precise parameter measurements would further rectify this issue, fitting the correlations and regressions closer to unity. Reasonably, empirical parameters should be recorded for cellular systems to be used in future HTS.

In Vivo Considerations: mFET 144 hpf Time Point. For the eight veterinary pharmaceuticals, Carlsson et al. recorded adverse effects up to $144 \mathrm{hpf}^{58}$ (Supporting Information 2, sheet "mFET data"). We used the latter to compute $C_{\text {int;aq }}$ at $144 \mathrm{hpf}$ to compare with estimates at $48 \mathrm{hpf}$. Hence, it might be vital to claim that we are comparing in vitro cellular concentrations to in vivo fish embryo concentrations, especially when including the $144 \mathrm{hpf}$ values, which are around the start of independent feeding. However, the mFET beyond $120 \mathrm{hpf}$ has to be interpreted as a low-tier in vivo system given that both toxicokinetic and toxicodynamic processes are not equal to adult fish ${ }^{60}$ and might deviate for some compounds from AFT data. $^{71}$
Median potency ratios at $144 \mathrm{hpf}$ are mostly comparable to $48 \mathrm{hpf}$, and changes in patterns due to bioavailability are identical (Figure S25). Doramectin, ivermectin, and toltrazuril are marginally more toxic in the mFET assay at $144 \mathrm{hpf}$ as compared to $48 \mathrm{hpf}$. An extended exposure period might lead to accumulated adverse effects. Beyond that, the zebrafish embryo is encapsulated within a chorion until approximately $72 \mathrm{hpf}$. The chorion might act as a barrier as well as a structural sink for lipophilic compounds and therefore might alter uptake kinetics. ${ }^{60,61}$ Alternatively, most of the tested compounds were reported to drop in measured concentrations at $144 \mathrm{hpf}^{58}$ due to metabolization. Bioactivation of metabolites might lead to increased toxicity. Febantel shows an approximately fivefold increase in toxicity between 48 and 144 hpf. Carlsson et al. ${ }^{58}$ demonstrated the metabolization of febantel into fenbendazole and further into oxfendazole within the embryo. Fenbendazole induces toxicity at lower concentrations compared to febantel (Figure S21; Supporting Information 2, sheets "cell data" and "mFET data"). Therefore, the shift in potency might be due to the metabolism-derived bioactivation of febantel. Accordingly, Pearson correlations are slightly lower between in vitro and in vivo data at $144 \mathrm{hpf}$ compared to $48 \mathrm{hpf}$ (Figure S28). The latter phenomenon could be reverted by including a metabolic activating system (liver microsomes) to the cytotoxicity assays, as has been done elsewhere for the FET. ${ }^{72}$

Studies have shown that the sensitivity to a compound does not increase substantially at $24 \mathrm{hpf}$ in the FET. ${ }^{20,21}$ However, the latter statement does not apply to all compound classes, ${ }^{2,71}$ which is still being reflected in very high correlations in certain arrangements that are omitting specific sources $\left(\mathrm{IC}_{50 \text { :free }}\right.$ vs $\mathrm{IAEC}_{50}$ in NRf-ZF4: adj. $R^{2}=0.93$ ). Conclusively, we postulate, at least for the compounds tested in this study, that cytotoxicity measurement in zebrafish cell lines is an appropriate predictor of AFT toxicity if the FET is considered as a bridging platform (Figure 4).

Approach Verification to Show the General Applicability. Rodrigues et al. compared the nominal effect concentrations of AFT data to cytotoxicity data derived from 
rat cardiomyoblasts and data from the literature. They found good correlations for the investigated group of pharmaceuticals ${ }^{42}$ but not for the investigated group of pesticides, ${ }^{43}$ which caused subsequent controversies regarding their conclusions. $^{44,45}$ Our data reflect the pesticide study quite well, with compounds showing a broad range of potencies, regarding the induction of cytotoxicity. We define the tested compounds in regard to their utilization as veterinary pharmaceuticals, but in terms of their classes, they could also be defined as pesticides. In this context, we postulate that most of the effects in the Rodrigues et al. pesticide study would correlate stronger between in vitro and in vivo if proper modeling of their bioavailable concentrations were applied.

To prove our postulation, we modeled the bioavailable effect concentrations of a set of compounds from the Rodrigues et al. pesticide study (10 additional compounds, 5 additional compound classes; see Supporting Information 2, sheet "properties") and conducted comparisons in the same manner as for our dataset. Further details are given in Supporting Information 1, Section 2.6. In summary, the bioavailable effect concentrations of the in vitro data correlated appropriately to the in vivo data $\left(R^{2}=0.65\right.$; Figure $\left.S 30\right)$. We speculate that a measured or modeled unbound plasma concentration in the fish would further improve the correlations; e.g., our forward dosimetry approach could be combined with a reverse dosimetry approach in vivo, as conducted previously for AFT data. ${ }^{64,73,74}$ When FET data were correlated to the in vitro data instead of AFT data, the correlation fit nearly located on the line of unity $\left(R^{2}=0.75\right.$; Figure S31), as with our dataset. Conclusively, we assume that the above-named authors would have reasoned differently if bioavailable concentrations were applied originally. We are not questioning the outcome and integrity of the above-stated studies, but we are advocating the use of appropriate concentration measures when attending the prediction of acute in vivo toxicity from in vitro cytotoxicity.

\section{OUTLOOK AND PERSPECTIVES}

In vitro to in vivo extrapolation (IVIVE) has been termed "the philosopher's stone" of in vitro toxicology. ${ }^{75}$ IVIVE describes the qualitative or quantitative transposition of effects recorded in vitro to predict toxic exposure levels in vivo. ${ }^{76,77}$ Therefore, it belongs to a new test strategy to replace animal testing in toxicology and is part of a battery of methods to estimate toxic exposure levels using non-animal tests. A quantitative IVIVE (QIVIVE) is a holistic approach to in vivo exposure level prediction, combining in vitro and in silico techniques (NAMs), such as quantitative structure-activity relationship modeling (QSAR) and physiologically based toxicokinetic/dynamic modeling (PBTK/TD) ${ }^{78-80}$ (Figure 4). PBTK/TD models need, e.g., reliable in vitro biotransformation, distribution, and absorption-defining (ADME) test systems to be developed and evaluated. ${ }^{78}$ Such test systems are scarce in ecotoxicology, and most test systems cover only the evaluation of nonspecific toxicity (cytotoxicity assays). As mentioned above, a first step could be to unify our forward dosimetry approach in vitro with reverse dosimetry approaches in vivo using PBTK modeling, such as those conducted by Stadnicka-Michalak et al. and Brinkmann et al. ${ }^{64,73,74}$ Alternatively, integrated testing strategies (ITSs) could be utilized in the short term to evolve the field until the QIVIVE criteria are met. Here, the FET could be exploited within the AOP concept to bridge the gap between MIE and low-tier KE, as recorded in vitro, to $\mathrm{AO}$ on the individual level, as recorded with the AFT.
Considerably, the AFT suffers from its restrictions and pitfalls (no mechanistic information, a broad range of test species, limited replication, etc.) and would probably not be validated in its form according to current standards. ${ }^{81,82}$ Recently, Rawlings et al. explored and suggested the use of the FET in the threshold approach instead of the AFT. ${ }^{83}$ Paparella et al. suggested an integrated approach to testing and assessment (IATA) for acute fish toxicity, which omits the AFT as much as possible but instead utilizes the FET and accompanying NAMs. ${ }^{81}$ Contextually, with the data and results in this study, we propose that the FET could be complemented by fish cell line-based cytotoxicity assays.

This only stands entirely true for baseline toxicants or when the apical in vivo endpoints are in close mechanistic vicinity to the measured endpoint of cytotoxicity, as we have seen here, e.g., for the NR endpoints. As we pointed out earlier, it is not possible to relate the mechanism of toxicity from apical endpoints in the AFT, FET, or cytotoxicity assay. Cytotoxicity assays are assays of nonspecific toxicity and thus record mostly high-tier cellular effects (KE), which are several levels of biological complexity above the MIE. Solely, specific and reactive-toxicity assays, e.g., reporter-gene assays, can define MIE. Thus, such specific assays are appropriate sentinels for the assessment, classification, and potential prediction of MOA. ${ }^{73}$ Contrarily, most MoAs cannot be related to cytotoxicity endpoints, with a few exceptions (e.g., baseline toxicity, uncouplers). Accordingly, even big-data in silico studies using information derived from the CompTox database could not relate various in vitro biomarkers of toxicity to specific MoA even when applying PBTK modeling. ${ }^{84,85}$

In 2004, Heringa et al. still advocated for measuring real exposure concentrations ${ }^{69}$ given that antecedent MBMs were less refined. Nonetheless, they have anticipated a development that could turn most chemical concentration analyses obsolete in the future. ${ }^{31}$ In this study, we have shown the reliability and robustness of fish-derived cytotoxicity assays accompanied by state-of-the-science MBMs to predict effects in the FET and thus low-tier in vivo assays. If the FET is used as a linking platform in ITS and IATA, fish cytotoxicity assays could be utilized in future regulatory decision making (see also Supporting Information 1, Section 2.5 for a discussion of numerical estimate values from a risk assessment perspective). Furthermore, these approaches might facilitate the development of novel test systems to pave the way for QIVIVE in ecotoxicology. The described strategy is merging the strengths of the in vitro and in silico techniques, thereby covering all paradigms of the classic (reduction, replacement, refinement) ${ }^{9}$ and modern (reliability, relevance, regulatory acceptance) $)^{14}$ 3Rs.

\section{ASSOCIATED CONTENT}

\section{S1 Supporting Information}

The Supporting Information is available free of charge at https://pubs.acs.org/doi/10.1021/acs.est.0c04872.

Supporting Information 1: a detailed description of all material and methods; additional results and discussion: pilot experiments; $\mathrm{LDH}$ endpoint exclusion and discussion; 4P log-logistic regression of nominal concentrations; mFET concentration-response curves; nominal and bioavailable median effect/inhibition concentrations of the cytotoxicity assays and the mFET; CompTox bioactivity data; additional data on 
potency ratios; additional data on Pearson correlations and Deming regressions; the Rodrigues et al. dataset; a regulatory/risk assessment perspective (PDF)

In Supporting Information 2, raw data and calculations are given, depicted, and described. (XLS)

\section{AUTHOR INFORMATION}

\section{Corresponding Author}

Sebastian Lungu-Mitea - Department of Biomedicine and Veterinary Public Health, Swedish University of Agricultural Sciences, SE-750 07 Uppsala, Sweden; 이이.org/00000001-8192-9134; Email: sebastian.lungu@slu.se

\section{Authors}

Carolina Vogs - Department of Biomedicine and Veterinary Public Health, Swedish University of Agricultural Sciences, SE-750 07 Uppsala, Sweden

Gunnar Carlsson - Department of Biomedicine and Veterinary Public Health, Swedish University of Agricultural Sciences, SE-750 07 Uppsala, Sweden

Maximiliane Montag - Institute for Environmental Research, RWTH Aachen, D-52074 Aachen, Germany

Kim Frieberg - Department of Biomedicine and Veterinary Public Health, Swedish University of Agricultural Sciences, SE-750 07 Uppsala, Sweden

Agneta Oskarsson - Department of Biomedicine and Veterinary Public Health, Swedish University of Agricultural Sciences, SE-750 07 Uppsala, Sweden; O orcid.org/00000002-3134-7811

Johan Lundqvist - Department of Biomedicine and Veterinary Public Health, Swedish University of Agricultural Sciences, SE-750 07 Uppsala, Sweden

Complete contact information is available at: https://pubs.acs.org/10.1021/acs.est.0c04872

\section{Notes}

The authors declare no competing financial interest.

\section{ACKNOWLEDGMENTS}

This work was financially supported by the Swedish Research Council (grant no. 2015-03404). The authors thank Matilda Stein Åslund (SLU Uppsala, Sweden) for proofreading the manuscript.

\section{REFERENCES}

(1) The European Parliament and of the Council. Regulation (EC) No. 1907/2006 Concerning the Registration, Evaluation, Authorisation and Restriction of Chemicals (REACH); 2006; pp 1-520. http://data. europa.eu/eli/reg/2006/1907/oj.

(2) US EPA. The Frank R. Lautenberg Chemical Safety for the 21st Century Act: Frequent Questions. 2016, 1-67.

(3) European Commission. CIS WFD, Guidance Document No . 19, Surface Water Chemical Monitoring; 2009.

(4) The European Parliament and of the Council. Regulation (EC) No. 1831/2003 of the European Parliament and of the Council of 22 September 2003 on Additives for Use in Animal Nutrition; 2003.

(5) Regulation (EU) No. 528/2012 of the European Parliament and of the Council of 22 May 2012 Concerning the Making Available on the Market and Use of Biocidal Products; 2012; pp 1-123.

(6) The European Parliament and of the Council. Regulation (EC) No. 1107/2009 of the European Parliament and of the Council of 21 October 2009 Concerning the Placing of Plant Protection Products on the Market and Repealing Council Directives 79/117/EEC and 91/414/ EEC; 2009; pp 1-50.
(7) Goldberg, A. M. The Principles of Humane Experimental Technique: Is It Relevant Today? ALTEX 2010, 27, 25-27.

(8) Hartung, T. From Alternative Methods to a New Toxicology. Eur. J. Pharm. Biopharm. 2011, 77, 338-349.

(9) Russell, W. M. S.; Burch, R. L. The Principles of Humane Experimental Technique. 1959.

(10) NRC. Toxicity Testing in the 21st Century; National Academies Press: Washington, D.C., 2007. DOI: 10.17226/11970.

(11) Worth, A.; Barroso, J.; Bremer, S.; Burton, J.; Casati, S.; Coecke, S.; Corvi, R.; Desprez, B.; Dumont, C.; Gouliarmou, V.; Goumenou, M.; Gräpel, R.; Griesinger, C.; Halder, M.; Roi, A. J.; Kienzler, A.; Madia, F.; Munn, S.; Nepelska, M.; Paini, A.; Price, A.; Prieto, P.; Rolaki, A.; Schäffer, M.; Triebe, J.; Whelan, M.; Wittwehr, C.; Zuang, V. Alternative Methods for Regulatory Toxicology-A Stateof-the-Art Review; 2014. DOI: 10.2788/11111.

(12) Tannenbaum, J.; Bennett, B. T. Russell and Burch's 3Rs Then and Now: The Need for Clarity in Definition and Purpose. J. Am. Assoc. Lab. Anim. Sci. 2015, 54, 120-132.

(13) Halder, M.; Kienzler, A.; Whelan, M.; Worth, A. EURL ECVAM Strategy to Replace, Reduce and Refine the Use of Fish in Aquatic Toxicity and Bioaccumulation Testing; 2014. DOI: 10.2788/084219.

(14) Lillicrap, A.; Belanger, S.; Burden, N.; Pasquier, D. D.; Embry, M. R.; Halder, M.; Lampi, M. A.; Lee, L.; Norberg-King, T.; Rattner, B. A.; Schirmer, K.; Thomas, P. Alternative Approaches to Vertebrate Ecotoxicity Tests in the 21st Century: A Review of Developments over the Last 2 Decades and Current Status. Environ. Toxicol. Chem. 2016, 35, 2637-2646.

(15) Hartung, T. Lessons Learned from Alternative Methods and Their Validation for a New Toxicology in the 21st Century. J. Toxicol. Environ. Heal. Part B 2010, 13, 277-290.

(16) Ankley, G. T.; Bennett, R. S.; Erickson, R. J.; Hoff, D. J.; Hornung, M. W.; Johnson, R. D.; Mount, D. R.; Nichols, J. W.; Russom, C. L.; Schmieder, P. K.; Serrrano, J. A.; Tietge, J. E.; Villeneuve, D. L. Adverse Outcome Pathways: A Conceptual Framework to Support Ecotoxicology Research and Risk Assessment. Environ. Toxicol. Chem. 2010, 29, 730-741.

(17) OECD. Test No. 236: Fish Embryo Acute Toxicity (FET) Test. In OECD Guidelines for the Testing of Chemicals; Section 2; OECD, 2013. DOI: 10.1787/9789264203709-en.

(18) Strähle, U.; Scholz, S.; Geisler, R.; Greiner, P.; Hollert, H.; Rastegar, S.; Schumacher, A.; Selderslaghs, I.; Weiss, C.; Witters, H.; Braunbeck, T. Zebrafish Embryos as an Alternative to Animal experiments-A Commentary on the Definition of the Onset of Protected Life Stages in Animal Welfare Regulations. Reprod. Toxicol. 2012, 33, 128-132.

(19) OECD. Test No. 203: Fish, Acute Toxicity Test; OECD Guidelines for the Testing of Chemicals, Section 2; OECD, 2019. DOI: 10.1787/9789264069961-en.

(20) Lammer, E.; Carr, G. J.; Wendler, K.; Rawlings, J. M.; Belanger, S. E.; Braunbeck, T. Is the Fish Embryo Toxicity Test (FET) with the Zebrafish (Danio Rerio) a Potential Alternative for the Fish Acute Toxicity Test? Comp. Biochem. Physiol. Part C Toxicol. Pharmacol. 2009, 149, 196-209.

(21) Knóbel, M.; Busser, F. J. M.; Rico-Rico, Á.; Kramer, N. I.; Hermens, J. L. M.; Hafner, C.; Tanneberger, K.; Schirmer, K.; Scholz, S. Predicting Adult Fish Acute Lethality with the Zebrafish Embryo: Relevance of Test Duration, Endpoints, Compound Properties, and Exposure Concentration Analysis. Environ. Sci. Technol. 2012, 46, 9690-9700.

(22) Belanger, S. E.; Rawlings, J. M.; Carr, G. J. Use of Fish Embryo Toxicity Tests for the Prediction of Acute Fish Toxicity to Chemicals. Environ. Toxicol. Chem. 2013, 32, 1768-1783.

(23) Castaño, A.; Bols, N.; Braunbeck, T.; Dierickx, P.; Halder, M.; Isomaa, B.; Kawahara, K.; Lee, L. E. J.; Mothersill, C.; Pärt, P.; Repetto, G.; Riego Sintes, J.; Rufli, H.; Smith, R.; Wood, C.; Segner, H. The Use of Fish Cells in Ecotoxicology: The Report and Recommendations of ECVAM Workshop 47. ATLA Altern. to Lab. Anim. 2003, 31, 317-351. 
(24) Schirmer, K. Proposal to Improve Vertebrate Cell Cultures to Establish Them as Substitutes for the Regulatory Testing of Chemicals and Effluents Using Fish. Toxicology 2006, 224, 163-183.

(25) the International Organization for Standardization. ISO 21115:2019(en) Water Quality-Determination of Acute Toxicity of Water Samples and Chemicals to a Fish Gill Cell Line (RTgill-W1), 2019.

(26) Fischer, M.; Belanger, S. E.; Berckmans, P.; Bernhard, M. J.; Bláha, L.; Coman Schmid, D. E.; Dyer, S. D.; Haupt, T.; Hermens, J. L. M.; Hultman, M. T.; Laue, H.; Lillicrap, A.; Mlnař́ḱová, M.; Natsch, A.; Novák, J.; Sinnige, T. L.; Tollefsen, K. E.; von Niederhäusern, V.; Witters, H.; Županič, A.; Schirmer, K. Repeatability and Reproducibility of the RTgill-W1 Cell Line Assay for Predicting Fish Acute Toxicity. Toxicol. Sci. 2019, 169, 353-364.

(27) Segner, H. Cytotoxicity Assays with Fish Cells as an Alternative to the Acute Lethality Test with Fish. Altern. to Lab. Anim. 2004, 32, $375-382$.

(28) Gülden, M.; Mörchel, S.; Seibert, H. Comparison of Mammalian and Fish Cell Line Cytotoxicity: Impact of Endpoint and Exposure Duration. Aquat. Toxicol. 2005, 71, 229-236.

(29) Gülden, M.; Seibert, H. Impact of Bioavailability on the Correlation between in Vitro Cytotoxic and in Vivo Acute Fish Toxic Concentrations of Chemicals. Aquat. Toxicol. 2005, 72, 327-337.

(30) Kramer, N. I.; Krismartina, M.; Rico-Rico, Á.; Blaauboer, B. J.; Hermens, J. L. M. Quantifying Processes Determining the Free Concentration of Phenanthrene in Basal Cytotoxicity Assays. Chem. Res. Toxicol. 2012, 25, 436-445.

(31) Groothuis, F. A.; Heringa, M. B.; Nicol, B.; Hermens, J. L. M.; Blaauboer, B. J.; Kramer, N. I. Dose Metric Considerations in in Vitro Assays to Improve Quantitative in Vitro-in Vivo Dose Extrapolations. Toxicology 2015, 332, 30-40.

(32) Riedl, J.; Altenburger, R. Physicochemical Substance Properties as Indicators for Unreliable Exposure in Microplate-Based Bioassays. Chemosphere 2007, 67, 2210-2220.

(33) Hestermann, E. V.; Stegeman, J. J.; Hahn, M. E. Cell Culture Serum Alters the Uptake and Relative Potencies of Halogenated Aromatic Hydrocarbons in PLHC-1 Cells. Mar. Environ. Res. 2000, 50, 545-546.

(34) Gülden, M.; Mörchel, S.; Seibert, H. Factors Influencing Nominal Effective Concentrations of Chemical Compounds in Vitro: Cell Concentration. Toxicol. Vitr. 2001, 15, 233-243.

(35) Gülden, M.; Mörchel, S.; Tahan, S.; Seibert, H. Impact of Protein Binding on the Availability and Cytotoxic Potency of Organochlorine Pesticides and Chlorophenols in Vitro. Toxicology 2002, 175, 201-213.

(36) Seibert, H.; Mörchel, S.; Gülden, M. Factors Influencing Nominal Effective Concentrations of Chemical Compounds in Vitro: Medium Protein Concentration. Toxicol. Vitr. 2002, 16, 289-297.

(37) Knauer, K.; Lampert, C.; Gonzalez-Valero, J. Comparison of in Vitro and in Vivo Acute Fish Toxicity in Relation to Toxicant Mode of Action. Chemosphere 2007, 68, 1435-1441.

(38) Tanneberger, K.; Knöbel, M.; Busser, F. J. M.; Sinnige, T. L.; Hermens, J. L. M.; Schirmer, K. Predicting Fish Acute Toxicity Using a Fish Gill Cell Line-Based Toxicity Assay. Environ. Sci. Technol. 2013, $47,1110-1119$.

(39) Natsch, A.; Laue, H.; Haupt, T.; von Niederhäusern, V.; Sanders, G. Accurate Prediction of Acute Fish Toxicity of Fragrance Chemicals with the RTgill-W1 Cell Assay. Environ. Toxicol. Chem. 2018, 37, 931-941.

(40) Fischer, F. C.; Henneberger, L.; König, M.; Bittermann, K.; Linden, L.; Goss, K.-U.; Escher, B. I. Modeling Exposure in the Tox21 in Vitro Bioassays. Chem. Res. Toxicol. 2017, 30, 1197-1208.

(41) Bittner, L.; Klüver, N.; Henneberger, L.; Mühlenbrink, M.; Zarfl, C.; Escher, B. I. Combined Ion-Trapping and Mass Balance Models To Describe the $\mathrm{pH}$-Dependent Uptake and Toxicity of Acidic and Basic Pharmaceuticals in Zebrafish Embryos (Danio Rerio). Environ. Sci. Technol. 2019, 53, 7877-7886.
(42) Rodrigues, E. T.; Varela, A. T.; Pardal, M. A.; Sardão, V. A. Cell-Based Assays as an Alternative for the Study of Aquatic Toxicity of Pharmaceuticals. Environ. Sci. Pollut. Res. 2020, 27, 7145-7155.

(43) Rodrigues, E. T.; Varela, A. T.; Pardal, M. A.; Oliveira, P. J. Cell-Based Assays Seem Not to Accurately Predict Fish Short-Term Toxicity of Pesticides. Environ. Pollut. 2019, 252, 476-482.

(44) Schirmer, K.; Stadnicka-Michalak, J.; Belanger, S. E.; Blaha, L.; Bols, N. C.; Dyer, S. D.; Embry, M. R.; Fischer, M.; Halder, M.; Hermens, J.; Hultman, M. T.; Kramer, N.; Laue, H.; Lee, L. E.; Lillicrap, A.; Natsch, A.; Segner, H.; Tanneberger, K.; Tollefsen, K. E.; Werner, I.; Witters, H.; Zupanic, A. Cell-Based Data to Predict the Toxicity of Chemicals to Fish. Commentary on the Manuscript by Rodrigues et Al., 2019. Cell-Based Assays Seem Not to Accurately Predict Fish Short-Term Toxicity of Pesticides. Environmental Pollution 252:476-482. Environ. Pollut. 2019, 254, 113060.

(45) Pardal, M. A.; Oliveira, P. J.; Rodrigues, E. T. Correspondence Reply Referring to the Correspondence of Schirmer et Al. (2019) Received by Environmental Pollution Regarding the Publication Rodrigues et Al. (2019). Environ. Pollut. 2019, 254, 113059.

(46) Villeneuve, D. L.; Coady, K.; Escher, B. I.; Mihaich, E.; Murphy, C. A.; Schlekat, T.; Garcia-Reyero, N. High-Throughput Screening and Environmental Risk Assessment: State of the Science and Emerging Applications. Environ. Toxicol. Chem. 2019, 38, 12-26.

(47) Lungu-Mitea, S.; Oskarsson, A.; Lundqvist, J. Development of an Oxidative Stress in Vitro Assay in Zebrafish (Danio Rerio) Cell Lines. Sci. Rep. 2018, 8, 12380.

(48) Lungu-Mitea, S.; Lundqvist, J. Potentials and Pitfalls of Transient in Vitro Reporter Bioassays: Interference by Vector Geometry and Cytotoxicity in Recombinant Zebrafish Cell Lines. Arch. Toxicol. 2020, 123456789.

(49) Farfan, A.; Yeager, T.; Ph, D.; Moravec, R.; Niles, A.; Corporation, P. Multiplexing Homogeneous Cell-Based Assays. Cell Notes 2005, 16, 16-19.

(50) Schirmer, K.; Chan, A. G. J.; Greenberg, B. M.; Dixon, D. G.; Bols, N. C. Methodology for Demonstrating and Measuring the Photocytotoxicity of Fluoranthene to Fish Cells in Culture. Toxicol. Vitr. 1997, 11, 107-119.

(51) Dayeh, V. R.; Schirmer, K.; Lee, L. E. J.; Bols, N. C. Rainbow Trout Gill Cell Line Microplate Cytotoxicity Test. In Small-scale Freshwater Toxicity Investigations; Springer-Verlag: Berlin/Heidelberg, 2005; Vol. 1, pp 473-503. DOI: 10.1007/1-4020-3120-3_16.

(52) Schirmer, K.; Tanneberger, K.; Kramer, N.; Volker, D.; Scholz, S.; Hafner, C.; Lee, L.; Bols, N.; Hermens, J. Developing a List of Reference Chemicals for Testing Alternatives to Whole Fish Toxicity Tests. Aquat. Toxicol. 2008, 90, 128-137.

(53) Dayeh, V. R.; Bols, N. C.; Tanneberger, K.; Schirmer, K.; Lee, L. E. J. The Use of Fish-Derived Cell Lines for Investigation of Environmental Contaminants: An Update Following OECD's Fish Toxicity Testing Framework No. 171. Curr. Protoc. Toxicol. 2013, 56, $1-20$.

(54) Bopp, S. K.; Lettieri, T. Comparison of Four Different Colorimetric and Fluorometric Cytotoxicity Assays in a Zebrafish Liver Cell Line. BMC Pharmacol. 2008, 8, 8.

(55) Fischer, F. C.; Abele, C.; Droge, S. T. J.; Henneberger, L.; König, M.; Schlichting, R.; Scholz, S.; Escher, B. I. Cellular Uptake Kinetics of Neutral and Charged Chemicals in in Vitro Assays Measured by Fluorescence Microscopy. Chem. Res. Toxicol. 2018, 31, 646-657.

(56) Fischer, F. C.; Cirpka, O. A.; Goss, K.-U.; Henneberger, L.; Escher, B. I. Application of Experimental Polystyrene Partition Constants and Diffusion Coefficients to Predict the Sorption of Neutral Organic Chemicals to Multiwell Plates in in Vivo and in Vitro Bioassays. Environ. Sci. Technol. 2018, 52, 13511-13522.

(57) Weimer, M.; Jiang, X.; Ponta, O.; Stanzel, S.; Freyberger, A.; Kopp-Schneider, A. The Impact of Data Transformations on Concentration-Response Modeling. Toxicol. Lett. 2012, 213, 292298. 
(58) Carlsson, G.; Patring, J.; Kreuger, J.; Norrgren, L.; Oskarsson, A. Toxicity of 15 Veterinary Pharmaceuticals in Zebrafish (Danio Rerio) Embryos. Aquat. Toxicol. 2013, 126, 30-41.

(59) Ulrich, S.; Brown, T. N.; Watanabe, N.; Bronner, G.; Abraham, M. H.; Goss, K.-U. N. E. UFZ-LSER Database v 3.2 [Internet]. Leipzig, Deutschland, Helmholtz Zentrum für Umweltforschung - UFZ 2017.

(60) Braunbeck, T.; Böttcher, M.; Hollert, H.; Kosmehl, T.; Lammer, E.; Leist, E.; Rudolf, M.; Seitz, N. Towards an Alternative for the Acute Fish LC(50) Test in Chemical Assessment: The Fish Embryo Toxicity Test Goes Multi-Species-An Update. ALTEX 2005, 22, 87-102.

(61) Vogs, C.; Johanson, G.; Näslund, M.; Wulff, S.; Sjödin, M.; Hellstrandh, M.; Lindberg, J.; Wincent, E. Toxicokinetics of Perfluorinated Alkyl Acids Influences Their Toxic Potency in the Zebrafish Embryo (Danio Rerio). Environ. Sci. Technol. 2019, 53, 3898-3907.

(62) Weil, M.; Scholz, S.; Zimmer, M.; Sacher, F.; Duis, K. Gene Expression Analysis in Zebrafish Embryos: A Potential Approach to Predict Effect Concentrations in the Fish Early Life Stage Test. Environ. Toxicol. Chem. 2009, 28, 1970.

(63) Oliveira, R.; Grisolia, C. K.; Monteiro, M. S.; Soares, A. M. V. M.; Domingues, I. Multilevel Assessment of Ivermectin Effects Using Different Zebrafish Life Stages. Comp. Biochem. Physiol. Part C Toxicol. Pharmacol. 2016, 187, 50-61.

(64) Stadnicka-Michalak, J.; Tanneberger, K.; Schirmer, K.; Ashauer, R. Measured and Modeled Toxicokinetics in Cultured Fish Cells and Application to In Vitro-In Vivo Toxicity Extrapolation. PLoS One 2014, 9, No. e92303.

(65) Heusinkveld, H. J.; Westerink, R. H. S. Comparison of Different in Vitro Cell Models for the Assessment of Pesticide-Induced Dopaminergic Neurotoxicity. Toxicol. Vitr. 2017, 45, 81-88.

(66) Goss, K.-U.; Bittermann, K.; Henneberger, L.; Linden, L. Ehquilibrium Biopartitioning of Organic Anions-A Case Study for Humans and Fish. Chemosphere 2018, 199, 174-181.

(67) Henneberger, L.; Goss, K.-U. Environmental Sorption Behavior of Ionic and Ionizable Organic Chemicals. In Reviews ofEnvironmental Contamination and Toxicology; 2019; Vol. 238, pp 22-28. DOI: $10.1007 / 398 \quad 201937$.

(68) Gülden, M.; Seibert, H. In Vitro-in Vivo Extrapolation: Estimation of Human Serum Concentrations of Chemicals Equivalent to Cytotoxic Concentrations in Vitro. Toxicology 2003, 189, 211-222.

(69) Heringa, M. B.; Schreurs, R. H. M. M.; Busser, F.; Van Der Saag, P. T.; Van Der Burg, B.; Hermens, J. L. M. Toward More Useful In Vitro Toxicity Data with Measured Free Concentrations. Environ. Sci. Technol. 2004, 38, 6263-6270.

(70) Wetmore, B. A. Quantitative in Vitro-to-in Vivo Extrapolation in a High-Throughput Environment. Toxicology 2015, 332, 94-101.

(71) Scholz, S.; Klüver, N.; Kühne, R. Analysis of the Relevance and Adequateness of Using Fish Embryo Acute Toxicity (FET) Test Guidance (OECD 236) to Fulfil the Information Requirements and Addressing Concerns under REACH; 2016.

(72) Mattsson, A.; Ullerås, E.; Patring, J.; Oskarsson, A. Albendazole Causes Stage-Dependent Developmental Toxicity and Is Deactivated by a Mammalian Metabolization System in a Modified Zebrafish Embryotoxicity Test. Reprod. Toxicol. 2012, 34, 31-42.

(73) Brinkmann, M.; Eichbaum, K.; Buchinger, S.; Reifferscheid, G.; Bui, T.; Schäffer, A.; Hollert, H.; Preuss, T. G. Understanding Receptor-Mediated Effects in Rainbow Trout: In Vitro-In Vivo Extrapolation Using Physiologically Based Toxicokinetic Models. Environ. Sci. Technol. 2014, 48, 3303-3309.

(74) Stadnicka-Michalak, J.; Schirmer, K. In Vitro-In Vivo Extrapolation to Predict Bioaccumulation and Toxicity of Chemicals in Fish Using Physiologically Based Toxicokinetic Model; 2019, 187-201, DOI: 10.1007/7653 201934.

(75) Kisitu, J. Chemical Concentrations in Cell Culture Compartments (C5) - Concentration Definitions. ALTEX 2019, 36, 154160.
(76) OECD. Guidance Document on Good In Vitro Method Practices (GIVIMP); OECD Series on Testing and Assessment; OECD, 2018. DOI: $10.1787 / 9789264304796$-en.

(77) Blaauboer, B. J. Biokinetic Modeling and in Vitro - in Vivo Extrapolations. J. Toxicol. Environ. Heal. Part B 2010, 13, 242-252.

(78) Wilk-Zasadna, I.; Bernasconi, C.; Pelkonen, O.; Coecke, S. Biotransformation in Vitro: An Essential Consideration in the Quantitative in Vitro-to-in VivoExtrapolation (QIVIVE) of Toxicity Data. Toxicology 2015, 332, 8-19.

(79) Yoon, M.; Campbell, J. L.; Andersen, M. E.; Clewell, H. J. Quantitative in Vitro to in Vivo Extrapolation of Cell-Based Toxicity Assay Results. Crit. Rev. Toxicol. 2012, 42, 633-652.

(80) Blaauboer, B. The Use of Biomarkers of Toxicity for Integrating in Vitro Hazard Estimates into Risk Assessment for Humans. ALTEX 2012, 29, 411-425.

(81) Paparella, M. Limitations and Uncertainties of Acute Fish Toxicity Assessments Can Be Reduced Using Alternative Methods. ALTEX 2020, DOI: 10.14573/altex.2006051, In Press..

(82) Braunbeck, T.; Böhler, S.; Knörr, S.; Lörracher, A.-K.; Pelka, K. E.; Kais, B. Development of an OECD Guidance Document for the Application of OECD Test Guideline 236 (Acute Fish Embryo Toxicity Test); 2020; Vol. 236.

(83) Rawlings, J. M.; Belanger, S. E.; Connors, K. A.; Carr, G. J. Fish Embryo Tests and Acute Fish Toxicity Tests Are Interchangeable in the Application of the Threshold Approach. Environ. Toxicol. Chem. 2019, 38, 671-681.

(84) Wetmore, B. A.; Wambaugh, J. F.; Ferguson, S. S.; Li, L.; Clewell, H. J.; Judson, R. S.; Freeman, K.; Bao, W.; Sochaski, M. A.; Chu, T.-M.; Black, M. B.; Healy, E.; Allen, B.; Andersen, M. E.; Wolfinger, R. D.; Thomas, R. S. Relative Impact of Incorporating Pharmacokinetics on Predicting In Vivo Hazard and Mode of Action from High-Throughput In Vitro Toxicity Assays. Toxicol. Sci. 2013, 132, 327-346.

(85) Becker, R. A.; Dreier, D. A.; Manibusan, M. K.; Cox, L. A.; Simon, T. W.; Bus, J. S. How Well Can Carcinogenicity Be Predicted by High Throughput "characteristics of Carcinogens" Mechanistic Data? Regul. Toxicol. Pharmacol. 2017, 90, 185-196. 